\title{
Research on the Humanistic Quality Education of Chinese Overseas Medical Students in "Virtual of Great Physician"
}

\author{
Mao Mingchen ${ }^{1, a}, F u$ Xinjun ${ }^{2, b^{*}}$ \\ ${ }^{1}$ Department of Humanities and Management, Shaanxi University of Traditional Chinese Medicine, Xianyang, \\ Shaanxi, China \\ amaomingchen728@126.com \\ b*fuxinjun402@126.com
}

\section{ABSTRACT}

Virtual of Great Physician is one of the medical ethics of medical students including medical students to study in China must learn, through mining the medical ethics and medical ethics culture, this paper will humanistic quality education into the Virtual of Great Physician course, medical students study for noble medical ethics guidance and education, make students in the diverse and western environment to establish the correct outlook on life and values and professional ethics, at the same time spread excellent traditional culture, communication between different cultures, finally achieve the dual gain of knowledge and moral cultivation.

Keywords: medical students, Virtual of Great Physician, humanistic quality education, medical ethics ideas

\section{《大医精诚》对中国海外医学留学生 人文素质教育的研究}

\author{
卯明琛 ${ }^{1, a}$ 付新军 $^{2, b *}$
}

\footnotetext{
${ }^{1}$ 陕西中医药大学, 咸阳, 陕西, 中国

amaomingchen728@126.com

b*fuxinjun402@126.com
}

\section{摘要}

《大医精诚》是我国医学生包括来华留学的医学生必学的医德文献之一, 通过挖掘其中的医德思想和医德文化, 本文将人文素质教育融入 “大医精诚” 课程当中，对来华留学的医学留学生进行高尚的医德医风引导与教育， 使学生在中西方多元复杂的环境中树立正确的人生观和价值观以及职业道德观念，同时传播中华优秀传统文 化，进行不同文化之间的交流，最终达到知识的传授和道德培养的双重增益。

关键词：医学留学生，大医精诚，人文素质教育，医德思想

\section{1. 前言}

《大医精诚》是中国古代著名医学家孙思䢬所著 书《备急千金药方》中第一卷的内容，其中所体现出 的医德医风思想为当代医生树立了良好的典范, 是习 医者必读的中医古籍文献, 有 “东方的希波克拉底誓 言”的称誉。
随着 “一带一路” 倡议的不断发展和深化以及中 国综合国力的不断加强, 来华留学生人数逐年递增, 大部分是求学而来, 而在求学留学生当中, 医学专业 的留学生又占比最大, 这是因为我国医学教育教学资 源丰富、政府奖学金丰厚、学费低廉等特点。医学留 学生作为高校学生队伍中的特殊群体, 招收医学留学 生的高校肩负着传道授业解惑的重任, 让学生在这个 
快节奏发展、物欲横流的世界保持着医者本心，树立 正确三观。

伴随着来华医学留学生人数的增长, 各种医学留 学生的教育问题也出现了。医德医风不仅仅成为我国 社会关注的热点, 外国医生同样也存在人文精神缺 失、医风不古的问题，高校逐渐认识到，除了传授专 业知识以外, 学生的思想道德修养的建设也很重要, 不论是本国学生还是外国学生, 高校应担负起“育人” 先 “育德” 的重任, 将人文素质教育融入课堂教学。

我国教育的优良传统一直都注重传道授业解惑、 育人育才有机统一。但课程中的人文素养和专门的人 文素养课程的概念得区分开来。课程中的人文素养是 将人文素养内容融入学生的课程学习当中, 在需要引 导的地方教师进行引导; 而专门的人文素养课堂则是 专门为培养学生的思想道德品质而开的一门课程, 这 在中国的中小学以及各高校都有开设, 需要值得注意 的是, 留学生来自世界各地, 有着不同的价值观和文 化背景, 学生不可能完全接受中国的思想品德教育课 程, 甚至会让学生产生抵触情绪, 还可能引发文化冲 突。

\section{2. 人文素质教育的必要性}

人文素质是指在人们在人文方面所具有的综合 品质或达到的发展程度。现代的 “人文主义” , 在很 大程度上是作为 “科学主义”、“金钱拜物教” 的对 立面而出现的。它相对于 “科学主义”, 强调的是关 注人的生命、价值和意义的人本主义; 相对于 “工具 理性” 或 “技术理性” ，强调的是价值理性和目的理 性; 相对于实用主义, 强调的是注重人的精神追求的 理想主义或浪漫主义。“科学”、“实用”与 “人文”、 “理想” 是人类生存和发展不可或缺的两个价值向 度。

我们得承认每个国家的价值观都不一样，但人类 追求美好的事物、品格的心是相通的, 我们传授给留 学生的价值观、人生观不仅要符合当今时代潮流, 更 要是人类相通的, 都认可的价值观念, 不过因为地域 原因, 留学生身处中国, 或多或少都会受到中国价值 观的影响, 教师也可适当向留学生介绍我们国家文 化、价值方面的优秀层面, 在课程进行的同时, 人文 素养也潜移默化影响着学生, 同时也进行了跨文化的 交流和中华文化的传播。

\section{1. 从国家层面}

针对当今世界普遍存着重科技、轻人文的倾向, 加强人文素质教育将在很大程度上克服目前由于教 育的太专门化所造成的科学与人文的分裂, 改变各专 门人才的 “单向度” 倾向, 使得 21 世纪高校所培养 的学生既有科学素养, 又富人文精神, 既有专业知识, 又有健全人格。这将是我国走向真正意义的现代文明
的可靠保证。

同时, 我国社会主义现代化国家的建设目标和中 国特色办学道路和方向, 需要良好的人文素养教育来 推动, 人文素养教育课程是中国特色社会主义高校的 必修课程和一直以来的优良传统, 只有培养了健全人 格、三观符合社会发展潮流的青少年, 国家才能保持 繁荣昌盛。来华留学生作为中国高校里的特殊队伍, 想要融入中国的大环境, 必须将人文素养教育融入到 课程当中, 让留学生深入了解中国, 积极主动弘扬中 华优秀传统文化, 如若运用得当, 更将有利于服务中 国新时代外交大局, 支援 “一带一路” 战略, 实现 “富 强、民主、文明、和谐”的中国。

\section{2. 从社会层面}

通过人文素质教育, 塑造学生的使命感和社会责 任感, 提高学生的职业道德素养和人才培养的质量, 推动我国高校和社会的稳定发展，实现“自由、平等、 公正、法治” 的良好社会氛围, 因此, 人文素质教育 是不可或缺的客观需要。

\section{3. 从个人层面}

从来华留学生的自身发展来看, 专业知识、技能 固然重要, 但人文素质教育是帮助学生身心健康发 展、塑造健全人格、树立正确价值观、达到 “爱国、 敬业、诚信、友善”道德规范的有效手段。

通过人文素质教育能够丰富来华留学生以及国 内大学生的精神世界, 培育他们的民族精神, 增强其 精神力量, 也可丰富他们的内在情感, 促使其情感智 慧的提升。

除了每个公民须遵守的基本道德规范以外, 各个 行业也都有自己的职业道德标准。比如医生, 救死扶 伤是天职, 应保持时刻为病人着想、廉洁奉公、钻研 医术, 精益求精等职业道德规范。将人文素养巧妙的 运用到《大医精诚》中, 有助于培养医学生的人道主 义精神和尊重生命、忠于职守、献身医学事业的崇高 品德和良好的职业道德。

以上从社会主义价值观谈了人文素质教育的必 要性, 是因为本文所浅析的《大医精诚》里所体现的 不管是医德思想还是医德文化, 都与当今社会主义核 心价值观所蕴含的内容和精神相吻合, 不仅对医者在 道德行为方面提出了高要求, 也对后世的医者起到了 良好的模范作用。

以社会主义核心价值观为指导, 挖掘《大医精诚》 中关于人文素养的内容, 实现知识和价值的共同增 益, 有利于增强留学生对中国优秀传统文化的认识和 了解, 提高留学生对中华传统文化的认同感, 积极主 动宣传推广中国文化，使我国教育逐步屹立于世界民 族之林。 


\section{3. 对医学留学生人文素养教育的对策}

\section{1. 方法运用上采取以情育情}

医学是一门科学精神与人文主义精神相结合的 一门学科, 科学精神注重实事求是、精确、精密; 人 文精神注重以人为本, 教人向善。目前, 一部分医学 生包括医学留学生缺乏人道主义情怀和责任感, 专业 课的老师也侧重培养学生的专业理论知识和实践能 力, 但以目前社会上医患关系紧张的情形来看, 现在 医学院校培养的医学生必须将科学的专业素养和人 文主义精神结合起来, 才能解决这一难题。

\section{1. 1. 一视同仁意识的培养}

一视同仁是医者最基本的人文主义情怀。

《大医精诚》开篇第二段就提到, 病者前来就医 时, 不论 “其贵贱贫富, 长幼妍虫, 怨亲善友, 华夷 愚智” 皆一视同仁, 当作自己的亲友对待, 常怀仁爱 之心。作为医者, 治病救人是天职, 而作为人, 免不 了会有生病的时候, 不能因为考虑自己的利弊得失, 担心自己的吉凶, 而瞻前顾后, 不积极为病人治疗。 孙思邀希望医者 “见彼苦恼, 若己有之, 深心凄怆”, 站在病人的角度思考, 将心比心, 感受病人的苦楚, 全心全意救护病人, 从而做到 “勿避险㟌, 昼夜寒暑, 饥渴疲劳, 一心赴救, 无作功夫行迹之心”。面对患 有疮痍、下痢、臭秽等的病人, 孙思邀希望医生表现 出的是发自内心的同情与难过, 不能对病人产生厌恶 的念头。

\section{1. 2. 敬畏生命意识的教育}

从古至今, 无数医者采用活物入药来救治患者, 在人们已有的观念里, 若是人和非人的生物做比较, 人总是比较高贵的。然而从珍惜生命来看, 人和其他 动物本质上是没有区别的, 孙思激认为, 损害别的生 命来挽救人的性命, 背离了 “生” 的道义, 而做到不 用活物给病人治病, 才是真正见识和技术超越寻常的 医者。如教导学生在上解刨课的时候, 不止对捐献遗 体的 “大体老师” 进行哀悼仪式, 对实验贡献生命的 小动物也需要进行哀悼仪式, 培养学生树立生命平等 和尊重生命的意识。

以上孙思邀所倡导的以病人为中心, 将仁爱之心 始终贯穿在整个救治过程中, 尊重和敬爱一切生命, 这都体现了医学的人文主义精神。

现如今医生和患者间的矛盾频发, 医闹事件数次 登上新闻, 积极促进医患关系的和谐, 有利于国家和 社会的稳定。

\section{2. 在价值指向上坚持以人为本}

\subsection{1. 医者仁心情怀的培养}

凡医者治病, 首先从内心出发, 做到 “安神定志, 无欲无求”, 然后树立做 “苍生大医” 的远大志向,

“誓愿普救含灵之苦”, 最后以病者为中心, 全心全 意为病者服务, 并常怀济世救人的热忱、悲悯和慈爱 之心。在《大医精诚》外, 还可以给学生拓展一下其 他医者仁心的小故事, 比如说 “杏林春暖” , 讲的是 三国时期的名医董奉, 无偿给病人看病, 但他有一个 要求, 每治好一个小病, 病人给他种下一棵杏树; 每 治好一个大病, 病人给他种下五棵杏树, 随着越来越 多的被治好的病人和时间的流逝, 杏树变成了杏林, 待到杏树结果, 董奉又用果子换取粮食, 以此去救助 穷苦的人民, 这就是被后世誉为 “杏林春暖” 的故事, 温暖的医德故事总是如渌渌流水一般打动人们的心。

再者, 如 2020 年末, 武汉新冠疫情突如其来, 全国人民团结一心，共同抵御疫情，各地医者，纷纷 驰援武汉, 尤其钟南山院士, 在疫情最为严重的时候, 毅然奔赴武汉前线支援。同时在境外疫情爆发最为严 重的时候, 我国的医疗救援队伍或是医疗物资, 也纷 纷前往韩国、日本、巴基斯坦等国家进行援助, 本着 滴水之恩, 当涌泉相报以及人类共同体的原则, 作为 负责任的大国和怀有仁爱之心的医生们自然不能够 做到袖手旁观。

\subsection{2. 清正廉洁作风的训练}

一个德艺兼优的医者, 能做到 “澄神内视, 望之 俨然, 宽裕汪汪, 不皎不昧”, 去到病者家里就诊时, “纵绮罗满目, 勿左右顾眝; 丝竹凑耳...... 夫一人 向隅, 满堂不乐, 而况病人苦楚, 不离斯须, 而医者 安然欢娱, 傲然自得, 兹乃人神之所共耻, 至人之所 不为, 斯盖医之本意也。”不被外物所诱惑、不贪图 享乐、不爱慕虚荣、不享用美味佳肴, 只因想到了病 人的痛苦, 医生便不能安心无虑得高兴娱乐。孙思邀 在此倡导了作为医者正确的义利观，他认为医生自己 悠然享乐, 置病人的痛苦于不顾, 这样的行为人神都 会觉得不耻, 作为一个道德高尚的医者, 不会做出这 样的事。

在物欲横流的当下社会, 同时随着经济高速发 展, 每行每业都存在作风不良的工作者, 作为医生, 在穿上白大补的时候, 在进行医学宣誓的时候, 意味 着肩上所担负的责任和希望，始终保持着一颗救世济 人的热忱之心, 学习孙思激一生清正廉洁、淡泊名利 的高尚品质和以一切病人为中心, 治病救人的医者初 心，不为钱权而去做违反医德的事。

在学校, 多关注医学生的心灵感受和情感体验, 多增加实践机会, 让学生有更多的机会和病患接触沟 通, 在与患者的交流中领悟医学中的人文主义精神; 也可以鼓励学生多参加公益性的服务活动, 切实融入 
医患情感体验当中去，体会《大医精诚》中孙思䇱不 计回报, 悬壶济世的高尚医德, 体会病人的痛苦, 领 悟敬重不管是人亦或是动物的生命。

\section{3. 创造良好的中医药文化教育环境}

学生的人文素质教育少不了老师的从中引导, 但 外部环境也必不可缺。一个良好的教育教学氛围可为 人文素质教育增益良多。可以借助校园已有的医药文 化资源, 如陕西中医药大学南校区, 在校内设有药园, 每种种植的药材都有标识牌, 上面注明药材的名称、 药性以及药用; 在图书馆以及校门口均设有 “药王” 孙思貌的塑像, 介绍了他的生平、著作以及精神; 在 学校的中央还设有五行园以及八卦图像; 还有校医史 馆, 每年新生都会组织安排前去参观, 会有专门的讲 解员进行讲解, 其中还包括一些珍稀药材, 以上这些 都可让学生处在一个中医药文化的氛围里, 潜移默化 的熏陶着学生, 结合老师的人文素质教育, 领悟其“大 医精诚”的真谛。

\section{4. 结论}

中华上下五千年的文明, 孕育出了博大精深的医 学以及大批济世爱民的苍生大医, 如董奉种杏成林、 神农尝百草等, 他们无私高尚的医德医风成为后辈学 习的楷模。医乃仁术, 古老的《大医精诚》充满人性 的对待病人, 将医学的科学和人道主义精神融合在了 一起, 将高尚的医德医风进行到底, 成为千古传诵的 医学佳话。

《大医精诚》被看作东方的“希波克拉底誓言”， 二者既有相同点也有不同点, 相同之处在于对医德的 阐述, 不同之处在于《大医精诚》更具有实操性, 思 想更为全面, 深入了解研究并将《大医精诚》融入到 课程思政当中, 不仅对国内医学生的医德培养很重 要, 对医学留学生而言也同样重要, 学习 “大医精诚”, 以大医精诚为志, 不忘医者本心, 常怀济世救人之心, 练就精湛的技术, 并用自己的一言一行去诠释 “大医 精诚” 的真谛, 无愧于 “精诚” , 无愧于 “大医”。

医生本就不是一个普通的职业, 在选择了医生这 个职业并穿上了白大社的那一刻, 也就相当于选择了 比常人多出不止一倍的耐心、廉洁、仁慈、公正等品 格。医生这个职业面对的是一条条鲜活的生命个体, 在面对患者的时候不容许有丝毫的懈急和差错出现, 在为病人开处方时, 能够自然而然站在病人的角度思 考: 这个方子、这个手术, 是否会为病人带来痊愈? 亦或者会为病人带来怎样的不良后果? 在对待患者 时是否充满了人道主义关怀? 让我们以本文所述 《大 医精诚》为志, 常怀有无私热忱的济世救人之心, 用 娴熟的技术医治病人，立做苍生之大医。

\section{REFERENCES}

[1] Sun Simiao.Essential prescriptions for emergency
preparedness[M]. Beijing: People's Medical Publishing House, 1998.

[2] Chen Yanzhen, Tao Jialei, Zou Xi, Liu Shenlin. Research on the Inherent Fit of Traditional Chinese Medicine Culture and Socialist Core Values [J]. Chinese Medical Ethics. 2017(11):1423-1426+1436

[3] Wang Hongsong, Xu Guolong, Zhang Jian, Shao Furong. Talking about the humanistic spirit of traditional Chinese medicine from Sun Simiao's medical ethics [J]. Clinical Journal of Chinese Medicine. 2008(05): 541-542

[4] Cao Sijia. An analysis of the medical ethics and its modern value in "Great Doctor Jingcheng" [J]. Journal of Changsha University. 2015(06): 58-60

[5] Li Jun, Li Yajun, Ma Zhen, Zhang Xueling. Research on the path of integrating the medical ethics of "Great Doctor Sincere" into the medical ethics education of contemporary medical students [J]. Chinese Medical Ethics. 2019(09): 1212-1216

[6] Zhou Zuliang, Lu Yuanhong. The value and application of ancient medical ethics literature to medical students' ideological and political education [J]. Journal of Guangxi University of Traditional Chinese Medicine. 2018(04):153-156

[7] Tian Yuan, Pan Linlin, Pang Guowei. Ideological and political education of students from the perspective of traditional Chinese medicine culture [J]. Modern Distance Education of Chinese Medicine. 2017(16): 16-18

[8] Meng Qingguo,Shao Zhenzhen.Research on the humanistic quality education of overseas Chinese medical students from the perspective of the second classroom $[\mathrm{J}]$. Health Vocational Education,2018,36(13):46-48.

[9] Huang Yiling,You Chengcheng,Lu Hua,Ni Yiran,Wang Yanhua,Tang Qincai.Thinking and practice of cultivating international students' medical humanistic quality in pathology teaching[J].Education Teaching Forum,2020(10):222-223.

[10] Shan Bin. Thoughts and measures on strengthening the humanistic quality education for international students in China[J]. Shanxi Youth, 2018(24): 70.

[11] Hu Xiaoyan, Xiang Li, Jiang Liang. The cultivation of humanistic spirit in the teaching of medical microbiology for international students[J]. Southwestern Military Medicine, 2013, 15(03): 356-357. 